\title{
MARIA STUART DE SCHILLER EM TRADUÇÃO DE MANUEL BANDEIRA
}

\author{
Daniel Martineschen 1 \\ ${ }^{1}$ Universidade Federal de Santa Catarina, Florianópolis, Santa Catarina, Brasil
}

\begin{abstract}
Resumo: "Brilhante”, "bela”, "erudita”, “poética”, "rebuscada”, "mais que poética", de "fluidez belíssima", "superior", "rigorosa”, "inspiradíssima" e "magistral”. É com tais termos laudatórios que se tem avaliado a tradução do drama Maria Stuart de Friedrich Schiller, realizada e publicada por Manuel Bandeira em 1955 e encenada desde setembro desse mesmo ano. A crítica de teatro e literária atribuem com unanimidade à tradução de Bandeira qualidade literária e apuro linguístico indiscutivelmente perfeitos, seja no que diria respeito à "fidelidade" ao texto schilleriano, seja quanto ao trabalho de texto, seja ainda quanto à efetividade em cena. Contudo, esse louvor irrestrito parece carecer de leitura mais cerrada do texto de Bandeira, cedendo assim a uma reverência que parece obscurecer toda crítica mais fina. Neste trabalho procuramos examinar causas e efeitos da tradução bandeiriana de Maria Stuart, no que diz respeito tanto à recepção do espetáculo quanto à matriz crítica que instruiu o trabalho tradutório, com base na noção de projeto de tradução proposta por Antoine Berman. Palavras-chave: Friedrich Schiller; Maria Stuart; Tradução de Teatro; Manuel Bandeira
\end{abstract}

\section{SCHILLER'S MARIA STUART TRANSLATED BY MANUEL BANDEIRA}

\begin{abstract}
Brilliant", "beautiful", “erudite", "poetic", “exquisite", "more than poetic", "beautifully fluid", "superior", "rigorous", "most inspired" and "masterpiece". With such terms the critics have been reading Manuel Bandeira's 1955 translation of Friedrich Schiller's Maria Stuart into Portuguese. The literary and theater critics have always unanimously
\end{abstract}


praised Bandeira's translation's high quality and linguistic thoroughness as undoubtedly perfect. His translation is "faithful" to the original, carefully made and effective at the stage. However this praise seems to lack a more closed reading of Bandeira's translation and so reveres the translator-poet and silences any finer criticism. In this text I look for causes and effects of Bandeira's translation of Maria Stuart, examine the reception of the spectacle and the critical premises for Bandeira's translation project in the terms of Antoine Berman.

Keyword: Friedrich Schiller; Maria Stuart; Theater translation; Manuel Bandeira

Sou melhor que a minha fama.

Maria Stuart, ato III, cena 4

\section{Manuel Bandeira Tradutor}

Primeiramente façamos uma breve incursão em alguns trabalhos que tratam da relação de Manuel Bandeira com a tradução. No artigo "Bandeira, importador de poesia", Walter Costa (1986) analisa a postura algo ambígua de Bandeira com relação às obras que traduziu, que oscilavam de livros técnicos, romances de pouca expressão e peças de teatro (a maioria de autores consagrados), até a poesia dos mais variados poetas. Os primeiros Costa considera parte "do grande conjunto de atividades paraliterárias" (Costa 103) do poeta, que lhe serviam de complemento à renda $\mathrm{e}$ como exercício de domínio dos idiomas. A poesia e o teatro, por outro lado, dada sua variedade e fragmentação, representariam mais uma realização do "ideal do paideuma poundiano" (ibidem), segundo o qual se faria a "organização do conhecimento para que o próprio homem ou geração possa achar, o mais rapidamente possível, a parte viva dele e gastar o mínimo tempo com itens obsoletos" (Pound 12). Os poemas traduzidos por Bandeira seriam, portanto, fonte de inspiração e opções para o próprio fazer poético, locais de identificação de sensibilidade poética, e por isso Costa qualifica Bandeira "mais [como] importador de poesia que de poetas" (Costa 103). 
Opinião semelhante expressa José Paulo Paes, que dedica capítulo especial à atividade tradutória de Bandeira intitulado "Bandeira tradutor e o esquizofrênico incompleto". Paes estende a discussão de Costa - com uma recapitulação mais detalhada da carreira tradutória de Bandeira - com o intuito de identificar a teoria subjacente ao seu fazer tradutório, e evidencia a contradição inerente a ela. Bandeira, apesar de afirmar impossível a tradução de poesia, fez durante quase toda sua vida traduções "reconhecidamente bem logradas" (Paes 65), justamente traduções de poesia. Paes procurou interpretar essa contradição teoria-prática "à luz de um descompasso entre o poeta criador e o artesão tradutor" (Paes 35), pois Bandeira teria experienciado os dois tipos de atividade criativa e isso lhe teria possibilitado um ponto de vista equilibrado entre opacidade impossibilitadora e transparência total, mais evidente na sua prática do que na sua teoria. É a partir desse campo semântico da óptica que Paes delineia a noção de "refração tradutória" (Paes 61), segundo a qual a efetividade de uma tradução se mediria segundo a capacidade de esta conter "não a tradução exata das palavras, mas a expressão do mesmo sentimento, e até das mesmas imagens, sob forma diferente". Paes entende a tradução "como uma técnica de equivalência ou aproximação" para dessa forma "modalizar pragmaticamente a antítese traduzível/intraduzível” (Paes 62). Para Paes, portanto, o fazer tradutório de Bandeira se equilibra na modalização entre possibilidade e impossibilidade e tende à realização empírica da noção jakobsoniana da "equivalência na diferença" (Jakobson 65).

Alan Caldas Simões analisa, em seu artigo "Manuel Bandeira: o tradutor", a práxis e a teoria tradutórias de Bandeira de modo semelhante ao feito por Paes, e chega a conclusões semelhantes: "podemos inferir que Bandeira utilizava, dentre outros procedimentos de tradução, a técnica de tradução por equivalência aliada à busca por reproduzir na língua-terminal a significância do poema-fonte" (Simões 83). Interessante aqui é a menção da ligação entre concepções poéticas de Bandeira e Schiller - que o poeta modernista expressa em Itinerário de Pasárgada -, algo que pode 
contribuir para a análise do texto de Maria Stuart: "a poesia seria a ponte entre o subconsciente do poeta e o subconsciente do leitor" (Bandeira apud Simões 82) ${ }^{1}$.

\title{
Bandeira, Schiller e Gonçalves Dias
}

Em Itinerário de Pasárgada, Bandeira comenta sua reaproximação com o universo de língua alemã durante sua estada para tratamento de saúde em Clavadel, na Suíça:

\begin{abstract}
Essa estada de pouco mais de um ano em Clavadel quase nenhuma influência exerceu sobre mim literariamente, senão que me fez reaprender o alemão, que eu aprendera no Pedro II, mas tinha esquecido (de volta ao Brasil li quase todo o Goethe, Heine e Lenau) (Bandeira, Itinerário de Pasárgada: de poetas e poesia, 40$)$
\end{abstract}

A proximidade com o universo literário de língua alemã é identificável desde a juventude do poeta. Essa afinidade encontraria expressão também nos Poemas traduzidos, entre outros nos poemas de Hölderlin traduzidos a pedido de Otto-Maria Carperaux e que o poeta considerou "uma das maiores batalhas que pelejei na minha vida de poeta" (Bandeira, Itinerário de Pasárgada: de poetas e poesia, 102) ${ }^{2}$.

Nota-se, portanto, que a poesia de língua alemã tem papel significativo na formação do paideuma bandeiriano. Bandeira também tinha grande afinidade com o poeta romântico brasileiro que, por sua vez, também admirava a língua alemã e o Romantismo alemão:

${ }^{1}$ Bandeira, Manuel. Seleta em prosa e verso. Rio de Janeiro: José Olympio editora, 1979.

${ }^{2}$ Hölderlin está, juntamente com Emily Dickinson e Juan Ramón Jiménez, no "ponto alto" dos poetas que Bandeira traduziu (Costa 105). Para análises mais alongadas sobre os poemas traduzidos por Bandeira, $c f$. também Simões.

Cad. Trad., Florianópolis, v. 41, no 3 p. 156-178, set-dez, 2021. 
Gonçalves Dias. O poeta da "Canção do exílio" denuncia essa admiração em algumas de suas obras, como a própria "Canção do Exílio", os dramas Patkull, Leonor de Mendonça e Boabdil, este último com claras referências schillerianas e somente "compreendida e apreciada na Alemanha, onde foi traduzida e posta em cena" (Jaccobi 41). A afinidade de Gonçalves Dias com o universo de língua alemã se deu também pela via tradutória, pois o poeta traduziu, além de poemas de Heine, Herder e Uhland, também $A$ noiva de Messina, um dos dramas da fase madura e histórica de Schiller. A tradução de Gonçalves Dias, iniciada em 1859, permaneceria na sua versão inicial, e a versão definitiva se tornaria lendária ao ter desaparecido no naufrágio de 1864 que subtraiu o autor precocemente à literatura brasileira. ${ }^{3}$

Esse elo entre a literatura brasileira e a de língua alemã - algo ainda a ser mais profundamente estudado pela fortuna crítica brasileira $^{4}$ - parece ter encontrado terreno fértil na sensibilidade de Manuel Bandeira, pois este tem débito incontestável para com Gonçalves Dias. Isso se atesta não somente na relação entre os poemas "Canção do exílio" e "Vou-me embora para Pasárgada", mas no cuidadoso trabalho de crítica nas várias obras sobre Gonçalves Dias que Bandeira escreveu e organizou: as Obras poéticas de Gonçalves Dias (Dias), uma seleção de poemas (Dias e Bandeira) e duas biografias do poeta (Bandeira, Poesia e vida de Gonçalves Dias) e (Gonçalves Dias: esbôço biográfico) ${ }^{5}$. Essa atividade editorial e crítica foi resgatada numa republicação recente da tradução de Gonçalves Dias de $A$ noiva de Messina, acrescida de notas

\footnotetext{
${ }^{3}$ Para uma análise mais detalhada das relações de Gonçalves Dias com a literatura alemã e em especial com o teatro de Schiller, $c f$. Volobuef.

${ }^{4}$ Considere-se, por exemplo, que ainda não se pesquisou com rigor a relação dos poetas românticos alemães com os românticos brasileiros, como por exemplo Uhland e Álvares de Azevedo.

5 Walter Costa aponta que a relação de Manuel Bandeira com Gonçalves Dias talvez tivesse mais a ver com trabalho por encomenda do que com uma afinidade estética do poeta; não é possível excluir, contudo, a possibilidade de ambas as coisas serem verdade.
} 
e comentários críticos de Manuel Bandeira quando da edição das Obras poéticas. Nota-se, em contraponto à esquizofrenia teórica de Bandeira quanto à tradução, um fino senso crítico a respeito do papel da tradução no fazer poético de Gonçalves Dias, que Márcio Suzuki, editor desta edição, ressalta no prefácio:

A edição seguida neste volume é a das Obras poéticas de
Antônio Gonçalves Dias, publicadas em 1944 pela Com-
panhia Editora Nacional, com organização, 'apuração do
texto', cronologia e notas de Manuel Bandeira. Pela funda-
mental importância para a compreensão da arte poética do
escritor romântico, o presente volume também reproduz as
notas de Bandeira ao texto da tradução (Schiller, A noiva
de Messina, ou, Os irmãos inimigos: tragédia em coros, 8).

O termo "apuração do texto" não foi posto entre aspas à toa por Suzuki. Apesar de essa edição não discutir diretamente o trabalho editorial de Bandeira, ela destaca a preocupação - e em alguns casos, a intervenção - textual do poeta modernista com relação à eficácia oral do texto teatral traduzido. As notas de Bandeira à tradução gonçalviana dão mostra dessa preocupação, e se referem a vários aspectos do texto, como escansão e enunciação (nota 4: "Leia-se 'exp'rimente",; nota 18: "Pronuncie-se 'túm'lo"”; nota 38: “ 'Não há': elisão violenta” etc.), alternativas de tradução (nota 5: "Variante: 'Tal é a lei, e o direito o exige"” para o verso "É isso a lei; isso o direito exige"), gralhas de edição (nota 7, 25), métrica (nota 12: "O verso tem onze sílabas, mas a vogal inicial se embebe no verso anterior”), esclarecimentos a referências de Schiller à literatura clássica (nota 19 sobre "Os irmãos tebanos"), entre outras.

O que se sobressalta nas notas de Bandeira, além de um cuidado de editor e de cotejo com o texto de Schiller (apesar de não haver indicação da edição original), é uma preocupação com a fluidez do texto, possivelmente, com vistas à encenação. É o caso, por exem- 
plo, da nota 54, que comenta o verso "Para das horas ocupar o vácuo" da seguinte maneira: "Variante: 'Para encurtar a vacuidez das horas'. Os dicionários não registram 'vacuidez', que parece neologismo formado, e mal formado, pelo poeta" (Schiller, A noiva de Messina, ou, Os irmãos inimigos: tragédia em coros, 57). O comentário de Bandeira se justifica por ensejar uma fluência maior do texto traduzido, e dá um claro exemplo da intervenção crítica do poeta sobre a tradução que edita.

O trabalho crítico de Bandeira na edição da tradução gonçalviana de $A$ noiva de Messina apresenta grande preocupação do poeta com a fluidez declamatória ou, talvez, com a consistência do texto no que tange à métrica e à forma. Além disso, se aceitarmos a hipótese de que Gonçalves Dias faz parte do paideuma bandeiriano, o trabalho cerrado com a tradução de $A$ noiva de Messina pode ter sido terreno fecundo para soluções tradutórias do próprio Manuel Bandeira ${ }^{6}$.

\section{Maria Stuart e o Teatro Brasileiro de Comédia}

Maria Stuart, escrito em 1799 e encenado pela primeira vez em 1800, é um dos pontos altos da obra dramatúrgica de Friedrich Schiller (1759-1805). Para além da trilogia Wallenstein e da peça Don Carlos, Maria Stuart se inseria no projeto de educação do ser humano por meio do teatro, confluência de um crescendo da representação (bastante idealizada) de ideais de igualdade:

Se o marquês de Posa em Don Carlos (1787) demandava liberdade de pensamento, a demanda por liberdade em $\mathrm{Ma}$ ria Stuart, de 1800, está totalmente interiorizada e depositada na subjetividade da heroína. Na luta entre as rainhas Elisabeth e Maria, as controvérsias morais e políticas são

\footnotetext{
${ }^{6}$ Uma dessas escolhas tradutórias é o uso de pronomes de tratamento em segunda pessoa do plural, que exige uma conjugação rigorosa e arcaizante, mas que mesmo assim não parece ter prejudicado a recepção da encenação de Maria Stuart.
}

Cad. Trad., Florianópolis, v. 41, nº 3 p. 156-178, set-dez, 2021. 
tratadas em um nível tão elevado que é difícil perceber as relações com a realidade alemã (Beutin et al. 199)

O drama relata a conflituosa relação entre as primas-irmãs aspirantes ao trono da Inglaterra, Maria Stuart - rainha católica da Escócia - e Elisabeth I - rainha protestante da Inglaterra. A fidelidade histórica - as duas nunca se encontraram - é sacrificada em favor da tensão dramática, que "cresce implacável rumo a uma cena inesquecível, criada pela imaginação do poeta e não pela realidade" (Guzik 84). De fato, a ação em Maria Stuart é acelerada e desconcertante, como atesta Julia Lemmertz em reportagem sobre a peça: "O texto é lindo e cada ação leva a outra. Quando o espetáculo começa é como se um pavio se acendesse" (Néspoli). Maria Stuart faz parte do repertório consagrado do teatro universal, e apresenta um "grande painel humano" que "é até hoje um instante insuperado do teatro" (Guzik 84).

Uma encenação de Maria Stuart seria, portanto, de primeiro interesse de qualquer companhia teatral com um público ávido por obras consagradas do teatro universal. Esse foi o caso do Teatro Brasileiro de Comédia (TBC), fundado em 1948 pelo empresário italiano Franco Zampari e que profissionalizou e revolucionou o modo brasileiro de fazer teatro. O público do TBC era a elite cafeeira paulistana, ávida por obras consagradas - sinônimo de prestígio e refino intelectual - e por comédias ligeiras - alívio e diversão fácil. A necessidade de tradução de repertório internacional era grande, e Lia Wyler comenta o critério para escolha dos tradutores para os textos de maior prestígio:

Para valorizar os textos dos dramaturgos de maior peso literário, entregavam sua tradução a escritores em ascensão como Manuel Bandeira, Guilherme de Almeida, Carlos Drummond de Andrade, Cecília Meirelles, Onestaldo Pennafort e Péricles Eugênio da Silva Ramos, entre outros. (Wyler 103) 
Seguindo essa tendência, em 1955 encomendou-se a Manuel Bandeira a tradução de Maria Stuart para encenação pelo TBC sob direção de Ziembinski. A tradução foi publicada e encenada pela primeira vez em setembro desse mesmo ano e teve um sucesso arrebatador de público e crítica, cumprindo assim seu papel de obra clássica no repertório eclético do $\mathrm{TBC}^{7}$. Seguiram-se meses de sucesso, com "vinte e um mil espectadores em oitenta e nove sessões" (Guzik 122), contando inclusive as montagens no Rio de Janeiro e em Porto Alegre.

É opinião unânime da crítica - sobretudo em suplementos literários de jornais - que a tradução de Bandeira estava muito acima da média e ajudou o espetáculo a ser bem-sucedido. $\mathrm{O}$ fato de estar em decassílabos brancos rigorosamente metrificados não parece ter prejudicado a apreciação da peça pelo público. Além dos qualificativos mencionados no resumo deste texto, há manifestações bastante efusivas, como a de Miroel Silveira, crítico bastante severo, cujo comentário selecionamos por ser exemplar da opinião da crítica:

\begin{abstract}
Para escrever sobre Maria Stuart, a primeira palavra tem que ser indiscutivelmente sobre a tradução de Manuel Bandeira. Temos tido em São Paulo tal maré de traduções inqualificáveis [...] que quando nos sentamos na platéia e temos a segurança de não precisar a todo momento baixar a cabeça para escapar das pedradas que os tradittori [sic] colocaram na boca dos pobres intérpretes, erguemos as mãos aos céus e louvamos ao Senhor. No caso de Maria Stuart, teremos que louvar o Senhor várias vezes: não somente pela exatidão e beleza da versão de Bandeira, como pela peça em si, uma das mais perfeitas obras do teatro romântico, e principalmente pela poderosa encenação de Ziembinski (Silveira 170).
\end{abstract}

7 Existia já uma tradução em prosa feita por E. P. Fonseca (1946), que provavelmente não teve o mesmo apelo reverente do público por se tratar de um tradutor desconhecido e de estar em prosa.

Cad. Trad., Florianópolis, v. 41, no 3 p. 156-178, set-dez, 2021. 
Em nenhum dos demais artigos coligidos no livro $A$ outra crítica Miroel Silveira foi tão efusivo e laudatório quanto no texto dedicado a Maria Stuart. Seu comentário ${ }^{8}$ parece marcado por uma reverência pelo poeta tradutor, cuja competência no trato com o texto implicaria numa tradução irretocável. É notável a reverência também na avaliação do resenhista do Jornal do Brasil, quando da estreia da peça no Rio de Janeiro, ao comentar que "o TBC voltou a conquistar novo triunfo com apresentação da célebre tragédia de Schiller, Maria Stuart, numa superior tradução de Manuel Bandeira" (Jornal do Brasil).

A resenha de Henrique Oscar no Diário de Notícias, por sua vez, analisa esse dito sucesso cum grano salis e parece dar um importante passo crítico para a análise da tradução bandeiriana. Considerando as montagens de 1956 no Rio de Janeiro - menos bem-sucedidas do que as de São Paulo devido a um despreparo maior do elenco de apoio e a uma galopante deterioração da estrutura do TBC -, Oscar comenta que a preservação da forma versificada teria prejudicado a eficiência cênica da montagem do TBC, sobretudo porque "é certo que não dispomos no Brasil de atores para levarem a cabo validamente uma representação desse estilo, para o que se exige formação técnica e tradição inexistente entre nós" (Oscar apud Michalsky 225) ${ }^{9}$. Excetuando-se astros como Cacilda Becker, Cleyde Yáconis e Walmor Chagas, o elenco de apoio parecia mesmo ter problemas com a forma versificada do texto, o que deveria exigir adaptação por parte do diretor. Contudo, não há registros de edição de Ziembinski no texto de Bandeira, e o comentário de Oscar tenta enxergar a preocupação do tradutor:

${ }^{8}$ Em geral Miroel Silveira mencionada tradução da peça quando o considera inqualificável, ou quando o texto é extremamente bem sucedido. Chamam a atenção comentários contraditórios, como o relativo à tradução de Aconteceu às 5 e um quarto de Saint-Geniez: "Por que conservaram os tradutores o tratamento 'tu', inteiramente em desuso a não ser no Rio Grande do Sul?" (Silveira 185). O mesmo recurso foi usado por Bandeira e não parece ter incomodado o louvor do crítico, mesmo se considerarmos que Maria Stuart, escrita no século XVIII, é obra do "repertório clássico".

${ }^{9}$ Oscar, Henrique. "Maria Stuart”. Diário de Notícias, Rio de Janeiro, 18/03/1956. 
Não foi sem razão que Manuel Bandeira procurou suavizar os versos, de maneira que pudessem ser ditos quase como se fossem prosa. Ele sabia que o estilo declamatório não ia dar certo, em virtude da inexperiência dos nossos atores, do qual, obviamente, não são culpados. Ziembinski, podendo conduzir seus intérpretes de barco, teimou em atirá-los ao mar, embora ciente de que não sabiam nadar. E o resultado foi o único possível: afogam-se todos num oceano de declaração bombástica, de artificialismo (Oscar apud Michalsk 228). ${ }^{10}$

É importante, por fim, considerar a montagem de Ziembinski. O próprio diretor declara, de maneira bastante explícita, a centralidade do texto na encenação de Maria Stuart, aparentemente com reverência semelhante à de Miroel Silveira:

$\mathrm{O}$ foguete da palavra esbelta e brilhante, contra o fundo neutro e profundo, a brasa das emoções e paixões e o penache de poesia contra plácida e serena simplicidade do terreno do palco, eis como concebo cenicamente a inspirada obra literária de Schiller (Ziembinski apud Michalsky 225) ${ }^{11}$

Para Ziembinski, então, o texto em si proveria a tensão dramática de Maria Stuart. Assim, o diretor opta por uma cenografia mínima e coloca a responsabilidade nas mãos (ou nas bocas) do elenco. Talvez o ambiente declamatório pudesse atrapalhar o esforço de "fluidificação" empreendido por Manuel Bandeira, mas não é isso que se observa, sobretudo considerando a recepção calorosa da encenação na crítica.

${ }^{10}$ Tem opinião semelhante Paulo Francis, em artigo publicado em 1958 no Diário Carioca. Francis, Paulo. "Lembrança de Dois Espetáculos". Diário Carioca, 19/01/1958 (Michalsky 229).

${ }^{11}$ Ziembinski, Z. “A 'Maria' do Romantismo, ou Romantismo da 'Maria'”, artigo de programa de Maria Stuart, Teatro Brasileiro de Comédia, São Paulo, 1955. 
A centralidade do texto de Maria Stuart para a encenação parece ter impressionado não somente Ziembinski, mas também outros diretores que realizaram montagens da peça posteriormente. É o caso, por exemplo, de Antonio Gilberto que, nas montagens feitas em 2009 - com Julia Lemmertz no papel-título e Lígia Cortez como Elisabeth -, optou também por cenografia reduzida e figurinos discretos. Assim, "a montagem volta o foco para os atores - 13 no total - e texto - na erudita tradução de Manuel Bandeira" (Neves). Mais do que somente focar nos atores, a montagem deliberadamente opta pela forma declamatória, num gesto análogo ao de Ziembinski e que parece gozar de boa receptividade do público e do elenco mesmo "em tempos de reinado de comédias ligeiras na temática e na cronometragem" (Ibidem). É patente mais uma vez a reverência do elenco com relação ao texto - tanto de Schiller quanto de Bandeira - no comentário de Julia Lemmertz: "Poderíamos ter cortado, adaptado. É claro que são outros tempos, as pessoas têm menos interesse, disponibilidade. Mas a culpa é também da gente, que vai facilitando, perdendo a gana de destrinchar textos como esse" (Ibidem) ${ }^{12}$.

\section{A tradução de Maria Stuart}

Para além de um pernicioso "jogo dos sete erros", a crítica de tradução deveria se preocupar com "o significado da diferença" (Cardozo), ou seja, pesar o valor de uma tradução devido à sua diferença com relação ao original, e não apesar dela. Segundo Cardozo, que embasa sua argumentação sobretudo no Pour une

\footnotetext{
${ }^{12}$ As resenhas e comentários a partir de onde retiramos os termos laudatórios do início do nosso texto são todos unânimes em louvar, com bastante reverência, a qualidade do texto de Bandeira e não considerar a forma versificada como um empecilho à realização do espetáculo. As resenhas foram encontradas em versões online de jornais ou em blogs, facilmente encontráveis por uma busca por "Maria Stuart Manuel Bandeira" em qualquer site de buscas: Tarbach; Néspoli; Neves; SESC; Vicente; TBC.
} 
critique des traductions de Antoine Berman, uma crítica que se limita a apontar as diferenças como aspectos negativos da tradução é "uma prática que ignora a própria natureza crítica da tradução, que ignora o tradutor, como sujeito da prática de tradução, e toda a reflexão crítica que sustenta suas decisões" (Cardozo 115). O "jogo dos sete erros" em geral reflete uma perspectiva essencialista que coloca original e tradução em relação hierárquica, com o segundo sempre em posição inferior porque é segundo, ancilar. Por outro lado, se entendermos, como Berman, a tradução como uma "atividade de ordem crítica”, então a crítica de tradução, como salienta Cardozo, "passaria a ser entendida como 'a crítica de um trabalho que já é, por si só, resultado de uma atividade de ordem crítica' (Berman 41)" (Cardozo 103).

Para analisarmos a postura tradutória de Manuel Bandeira no projeto Maria Stuart, consideremos a complexa rede de influências, causas e efeitos mobilizada nesse fazer tradutório. Primeiramente, Manuel Bandeira realiza essa tradução sob encomenda de Franco Zampari para encenação pelo TBC. Apesar de ser uma encomenda, em vez de se configurar mais uma de suas "atividades paraliterárias" (Costa 103) esse encargo tradutório congrega afinidades que Manuel Bandeira tem de longa data e que pode mobilizar criativamente: com a língua e com a literatura alemã, com Schiller (intimamente ligada à afinidade que tem com Gonçalves Dias) e finalmente a afinidade com a tradução para teatro (adquirida durante o trabalho editorial sobre a tradução gonçalviana d'A noite de Messina de Schiller). São afinidades indissociáveis e que se retroalimentam, e tentaremos ressaltar uma ou outra ao analisar aspectos concretos do texto de Bandeira.

A tradução de Bandeira não pode ser chamada de "fiel" em qualquer sentido lato do termo. Em primeiro lugar, os nomes das personagens foram adaptados, em grande medida, para versões inglesas ou afrancesadas. Por exemplo, "Wilhelm" se torna "William", "Georg" se torna "George", e o "Graf Aubespine" ganha o nome afrancesado de "Conde de L'Aubespine”. Além de cuidar da fluidez da pronúncia, Bandeira parece dialogar com o teatro sha- 
kespeariano, ao qual Schiller também alude, e com a tradição literária francesa, de importância capital para a literatura brasileira ${ }^{13}$.

$\mathrm{O}$ texto de Schiller $^{14}$ foi escrito em decassílabos e eneassílabos brancos com ritmo iâmbico e vocabulário predominantemente oral, com tratamento ora formal (Ihr) ora pessoal $(d u)$ entre as personagens e apurado uso de esticomitia e antílabe no encaixamento dos diálogos. O que se nota na tradução de E. P. Fonseca é que ela foi concebida para ser publicada em formato de livro, sem colocar muitas restrições quanto a tamanho de verso ou facilidade de recitação. Por outro lado, o texto de Bandeira segue padrões formais similares aos do texto schilleriano, com o uso de decassílabos brancos, metro largo o suficiente para acomodar os monossílabos significativos alemães na nossa língua de paroxítonas. Essa opção formal parece aproximar os textos alemão e brasileiro, como se pode notar já no primeiro verso do primeiro ato:

Was macht Ihr, Sir? Welch neue Sir, que fazeis? Que nova audácia é Dreistigkeit! esta? ${ }^{15}$

(Schiller,Werke in vier Bänden, 386) (Schiller, Maria Stuart 1965, 19)

Dentro dos limites de trabalho que se impõe, o tradutor Bandeira produz o seu texto com a fidelidade que corresponde a esses limites. No verso citado também se nota a escolha consistente pelos tratamentos ingleses, Sir e Lady, e os correlatos Milady e Milord, ambos muito mais curtos que "senhor" e "senhora". Essa escolha também preserva a localização espaço-temporal da trama, a In-

\footnotetext{
${ }^{13}$ Estratégia diferente com relação aos nomes adotou o tradutor E. P. Fonseca ao abrasileirar todos os nomes, chamando Elizabeth de "Isabel", Georg Talbot de "Jorge Talbot", William Cecil de "Guilherme Cecil" e, finalmente, o "Graf Aubespine" simplesmente de "Conde de Aubespine" (Schiller, Maria Stuart I, 8). 14 Usei aqui da edição de obras completas em Schiller, Werke in vier Bänden,385-499). Nenhuma das traduções consultadas menciona a edição do texto original utilizada pelo tradutor.

${ }^{15}$ A opção de Fonseca: "Que é que está fazendo, senhor? Mais uma indignidade?" (Schiller, Maria Stuart I, 10).
} 
glaterra elisabetana. Quanto ao ritmo dos decassílabos, alterna-se entre sáfico e heroico, sendo este frequente nos monólogos mais inflamados como os de Elisabeth e de Maria na cena 4 do $3^{\circ}$ ato.

Maria Stuart é peça cuja tensão dramática se constrói com um crescendo ininterrupto, e a discussão entrecortada e a troca rápida de falas entre as personagens dita o ritmo quase frenético da ação. Seria desejável que o texto em português, pensado para encenação, mantivesse esse crescendo. Identificando o procedimento formal de Schiller, Manuel Bandeira preserva tanto quanto pode essa dinâmica dos diálogos, usando os recursos da esticomitia e da antílabe. O primeiro recurso, que corresponde à alternância rápida de falas curtas, e o segundo, que corresponde à partição de um único verso na fala de dois ou mais personagens, podem ser vistos na discussão entre Leicester e Mortimer sobre o plano para resgatar Maria Stuart, eivado de paixão, coragem e temeridade:

Leicester. Ich sag' Euch, Ritter, es ist nicht zu wagen.

Mortimer bitter.

Nein, nicht für Euch, der sie b e s i t $\mathrm{z}$ e $\mathrm{n}$ will!

Wir wollen sie bloß $\mathrm{r}$ e $\mathrm{t} \mathrm{t}$ e $\mathrm{n}$, und sind nicht so

Bedenklich

Leicester. Junger Mann, Ihr seid $\mathrm{zu}$ rasch

In so gefährlich dornenvoller Sache.

Mortimer. Ihr - sehr bedacht in solchem Fall der Ehre.

Leicester. Ich seh' die Netze, die uns rings umgeben.

Mortimer. Ich fühle Mut, sie alle zu durchreißen.
Leicester. Insisto, Cavaleiro: Não é para arriscar.

Mortimer (amargo) Não para vós,

Que desejais possuí-la! Nós queremos

Simplesmente salvá-la, e somos menos

Hesitantes.

Leicester. $\mathrm{O}$ golpe é perigoso Demais, e inçado de dificuldades. Sois excessivamente arrebatado. Mortimer. Vós, muito ponderado em caso de honra.

Leicester. Vejo os laços que em tôrno se nos armam.

Mortimer. Sinto a coragem de rompê-los todos! 
Leicester. Tollkühnheit, Raserei ist dieser Mut.

Mortimer. Nicht Tapferkeit ist diese Klugheit, Lord.

Leicester. Euch lüstet's wohl, wie Babington zu enden?

Mortimer. Euch nicht, des Norfolks Großmut nachzuah $\neg$ men.

Leicester. Norfolk hat seine Braut nicht heimgeführt.

Mortimer. Er hat bewiesen, daß er's würdig war.

Leicester. Wenn wir verderben, reißen wir sie nach.

Mortimer. Wenn wir uns

schonen, wird sie nicht gerettet.

(Schiller (Werke in vier Bänden) 435)
Leicester. É uma temeridade essa coragem.

Mortimer. Não é bravura, Sir, essa prudência.

Leicester. Apeteceis o fim de Babington?

Mortimer. Não imitais a generosidade

De Norfolk.

Leicester. Norfolk não voltou com a noiva.

Mortimer. Mostrou com isso que era digno dela.

Leicester. Se fracassarmos, morrerá conosco.

Mortimer. Se nos pouparmos, nunca a salvaremos!

(Schiller (Maria Stuart 1965) 88)

A escolha pela forma versificada para a tradução, ao impor as limitações de tempo e espaço de declamação, dá agilidade ao texto e assegura a velocidade da ação dramática que é presente no texto alemão. Essa agilidade e fluidez do texto talvez tenham auferido à tradução de Bandeira a caracterização de "prosa semiversejada" (Vicente). Como base de comparação, vejamos a versão em prosa de Fonseca, que se permite maior prolixidade:

LEICESTER - Repito-lhe, cavalheiro, não devemos nos arriscar.

MORTIMER (com amargor) - Não o senhor, que deseja possuí-la... Mas nós, que só queremos salvá-la, não refletimos tanto. 
LEICESTER - Moço, quer lançar-se num assunto arriscado e difícil?

MORTIMER - O senhor reflete demais nele.

LEICESTER - Porque vejo as ciladas que nos cercam por todos os lados.

MORTIMER - Sinto-me com ânimo para enfrentá-las.

LEICESTER - Insensatos, temeridade, loucura, eis em que se resume esse valor.

MORTIMER - A sua prudência, milorde, não é arrojo.

LEICESTER - Quer acabar como Babington?

MORTIMER - E o senhor não deseja imitar o ânimo valoroso e magnânimo de Norfolk?

LEICESTER - Norfolk não levou a sua amada ao altar. MORTIMER - Todavia provou que era digno de fazê-lo. LEICESTER - Se nos perdemos não conseguiremos libertá-la.

MORTIMER - E, tardando-nos, jamais consegui- remos salvá-la.

(Schiller, Maria Stuart, 74-75)

Como aponta Henrique Oscar, Manuel Bandeira tinha ciência de que o texto era destinado à encenação, e também de que nem sempre o elenco do TBC (composto em grande parte de atores amadores) tinha treinamento para recitar em versos. Assim, Bandeira parece ter procurado "suavizar os versos" (Oscar). Essa atenção é identificável já no trabalho editorial de Bandeira sobre $A$ noiva de Messina, por exemplo nas numerosas notas a respeito da pronúncia abreviada de vários versos. Bandeira, um poeta versado em muitas formas poéticas, demonstra sensibilidade fina para as especificidades de leitura do texto gonçalviano, em especial as "elisões violentas" sem as quais os versos não caberiam na métrica.

No que se refere às didascálias, Bandeira em geral reproduz aquelas constantes no original, em tradução bastante próxima. Em alguns casos, contudo, talvez num esforço para facilitar o trabalho dos atores, foram inseridas indicações cênicas onde havia um trecho de uma fala, como na fala de Elisabeth na cena 3 do $2^{\circ}$ ato 
citada abaixo. Podemos supor que este fosse o tratamento que Bandeira teria dado aos travessões indicadores de pausas (-); contudo, isso não é adotado consistentemente no texto como um todo, sendo as pausas desses travessões em geral ignoradas.

Sinnt einen mildern Rat aus - Edler Dai-me aviso mais brando.

Lord

(Voltando-se para Talbot.)

Von Shrewsbury! Sagt I h r uns E vós, Milord,

Eure Meinung.

Que aconselhais?

(Schiller, Werke in vier Bänden, (Schiller, Maria Stuart 1965, 67) 420)

Deve-se ainda comentar o uso de pronomes de tratamento "tu" e "vós", o primeiro usado nos diálogos entre pessoas com intimidade e o segundo nos diálogos entre membros da nobreza. Se a reputação de Manuel Bandeira não interditasse de antemão comentários pontuais às suas escolhas tradutórias, um comentário como o supracitado de Miroel Silveira, a respeito do uso do pronome "tu", já em desuso, seria perfeitamente aplicável a esta tradução. Porém, a escolha pelos pronomes "tu" e "vós" pode ter sido motivada por duas razões. Primeiramente, são monossílabas e portanto mais curtas que "você" e "vocês" - um item a se levar em conta na economia apertada da tradução em versos. Além disso, as conjugações na segunda pessoa são marcadas morfologicamente, o que permite ao tradutor prescindir dos pronomes em caso de urgência de espaço. Em segundo lugar, já na época de Schiller o tratamento formal de nobres por $I h r$ já estava caindo em desuso e sendo substituído pelo pronome Sie, ao passo que a nobreza também cedia seu lugar cada vez mais à burguesia. $\mathrm{O}$ uso desse pronome de tratamento, além de localizar a ação em um tempo em que a nobreza ainda concentrava todo o poder, performa uma crítica de matriz burguesa com relação justamente às tramas e intrigas que permeavam essa nobreza, conferindo às personagens um ar de irônico arcaísmo condizente com

Cad. Trad., Florianópolis, v. 41, no 3 p. 156-178, set-dez, 2021. 
a crítica schilleriana contra a realeza. A manutenção dessa forma de tratamento pelo tradutor Manuel Bandeira preserva essa crítica burguesa e mantém o tom arcaizante do texto, localizando a ação no tempo para que foi concebida. ${ }^{16}$

Por fim, cabe ainda breve comentário aos elementos paratextuais presentes nas edições da tradução de Manuel Bandeira. Em nenhuma delas é indicada a edição do texto original de que o tradutor se valeu para seu trabalho. Essa informação, contudo, talvez não fizesse diferença para a tradução feita para o TBC, pois a preocupação do diretor e do público seria a fruição do espetáculo. As duas edições a que tivemos acesso direto (a primeira edição de 1955 não foi encontrada) trazem textos de apresentação e introdução à biografia e à obra de Schiller. A apresentação na edição da Ediouro é assinada por Fausto Wolff, e a da Abril Cultural - longa e recheada de fotografias de montagens inglesas, francesas e brasileiras da peça - não tem autoria indicada. A tradução é precedida por um prefácio de Manuel Bandeira, que igualmente se limita a comentar a história e a repercussão da peça, sem mencionar aspectos textuais ou do processo de tradução. Ambas as edições apresentam uma ficha técnica da primeira montagem brasileira pelo TBC em 1955.

\section{Considerações finais}

O sucesso da tradução de Manuel Bandeira tanto em livro quanto em cena parece ter sido considerado certo e incontestável devido a um tipo de aura de infalibilidade do poeta como tradutor. Essa aura, contudo, não deveria obscurecer a análise de características intrínsecas à tradução de Bandeira e que a tornaram exemplar e

\footnotetext{
${ }^{16}$ Vale salientar que no texto de Schiller há variação no uso de $I h r$ e de $d u$, sobretudo quando se inverte ou alivia a relação hierárquica com a realeza. Manuel Bandeira procurou manter essa variação, como se nota no uso do "tu" entre Anna e Maria na cena 2 do $1^{\circ}$ ato (quando aquela comunica a esta a violação de seus pertences pessoais) e na retomada do "vós" na cena 4 do mesmo ato, quando Maria reforça sua majestade e assegura a Ana que não sucumbirá às agruras do cárcere.
} 
bem-sucedida. Ao ser consistente em suas opções tradutórias - escolhas métricas, registro, recursos de tensão dramática etc. - o poeta-tradutor logrou recriar em português a peça alemã com sua tensão dramática crescente e sua ação concentrada nas falas das personagens. Nos termos que propõe José Paulo Paes, a tradução de Bandeira é resultado de refração tradutória, desvio no caminho da luz do texto original proporcionado pelo prisma crítico de Manuel Bandeira, prisma este constituído organicamente pelas influências recebidas pelo poeta, filtradas por sua própria sensibilidade poética e concretizadas em procedimentos tradutórios pragmaticamente consistentes. Enunciar as afinidades tradutórias e literárias do poeta permitiu perceber, ainda que parcialmente, a formação desse prisma, que em sua composição cristalina forma e informa o texto traduzido pelo poeta. Assim, podemos compreender um pouco mais a complexidade e a preocupação crítica que caracterizam a prática tradutória de Manuel Bandeira e que realmente teriam causado o sucesso retumbante da sua tradução. A Maria Stuart de Schiller, equilibradora dos contrastes entre as rainhas irmãs e solene na sua linguagem fluente, transparece refratada pela pena de Manuel Bandeira, e dessa maneira o público leitor e espectador brasileiro pode conferir o que realmente dá à obra a sua fama.

\section{Referências}

Bandeira, Manuel. Gonçalves Dias: esbôço biográfico. Rio de Janeiro: Irmãos Pongetti, 1952.

Bandeira, Manuel. Gonçalves Dias: poesia. Rio de Janeiro: Agir, 1958.

Bandeira, Manuel. Poesia e vida de Gonçalves Dias. São Paulo: Américas, 1962. 
Bandeira, Manuel. Itinerário de Pasárgada: de poetas e poesia. Rio de Janeiro: Livraria São José, 1966, v. II.

Bandeira, Manuel. Seleta em prosa e verso. Rio de Janeiro: José Olympio editora, 1979.

Berman, Antoine. Pour une critique des traductions: John Donne. Paris: Gallimard, 1995.

Beutin, Wolfgang; Beilein, Matthias; Ehlert, Klaus; Emmerich, Wolfgang; Kanz, Christine; Lutz, Bernd; Meid, Volker; Opitz, Michael; Opitz-Wiemers, Carola; Schnell, Ralf; Stein, Peter; Stephan, Inge (orgs.). Deutsche Literaturgeschichte. Von den Anfängen bis zur Gegenwart. Stuttgart, Weimar: J.B. Metzler, 2013.

Cardozo, Mauricio Mendonça. "O significado da diferença: a dimensão crítica da noção de projeto de tradução literária". Tradução e Comunicação - Revista Brasileira de Tradutores, 5, (2009): 101-117.

Costa, Walter Carlos. "Bandeira, importador de poesia". Travessia, 5 (13), (1986): 102-108.

Dias, Antônio Gonçalves. Obras poéticas de A. Gonçalves Dias. Organização, apuração do texto, cronologia e notas por Manuel Bandeira. São Paulo: Nacional, 1944.

Dias, Antônio Gonçalves; Bandeira, Manuel. Gonçalves Dias: poesia. Rio de Janeiro: Agir, 1958.

Guzik, Alberto. TBC: crônica de um sonho. São Paulo: Perspectiva, 1986.

Jaccobi, Ruggero. Goethe, Schiller, Gonçalves Dias. Porto Alegre: Edições da faculdade de filosofia, 1958.

Jakobson, Roman. “Aspectos lingüísticos da tradução”. Lingüística e comunicação. tradução de I. Blikstein e J. P. Paes. São Paulo: Cultrix, 1969. 
Jornal do Brasil. "MARIA STUART" NO GINÁSTICO". Jornal do Brasil, 17 de março de 1956, 10.

Michalski, Yan. Ziembinski e o teatro brasileiro. São Paulo/Rio de Janeiro: Hucitec, 1995.

Néspoli, Beth. "Maria Stuart”. O Estado de São Paulo, São Paulo, 17 de setembro de 2009, disponível em < http://www.estadao.com.br/noticias/impresso,mariastuart, $436347,0$. htm $>$.

Neves, Lucas. "'Maria Stuart' de Schiller ganha os palcos de SP”. Folha de São Paulo, Seção "Acontece", 19 de dezembro de 2009, disponível em < http:// www1.folha.uol.com.br/fsp/acontece/ac1909200901.htm > .

Oscar, Henrique. "Maria Stuart”. Diário de Notícias, Rio de Janeiro, 18/03/1956.

Paes, José Paulo. Tradução: a ponte necessária. São Paulo: Ática, 1990.

Pound, Ezra. $A B C$ da literatura. Organização e apresentação da edição brasileira por Augusto de Campos. Tradução de José Paulo Paes e Augusto de Campos. São Paulo: Cultrix, 2013.

Schiller, Johann Christian Friedrich von. Maria Stuart. Tradução de E. P. Fonseca. Rio de Janeiro: Irmãos Pongetti, 1946. I

Schiller, Johann Christian Friedrich von. Maria Stuart. Tradução e prefácio de Manuel Bandeira. Rio de Janeiro: Civilização Brasileira, 1946. II

Schiller, Johann Christian Friedrich von. Werke in vier Bänden. V. 3. Leipzig: VEB Bibliographisches Institut, 1962.

Schiller, Johann Christian Friedrich von. Maria Stuart. Tradução e prefácio de Manuel Bandeira, apresentação de Fausto Wolff. Rio de Janeiro: Edições de Ouro, 1965.

Schiller, Johann Christian Friedrich von. (e) Maria Stuart. Tradução e prefácio de Manuel Bandeira. São Paulo: Abril Cultural, 1977. 
Schiller, Johann Christian Friedrich von. A noiva de Messina, ou, Os irmãos inimigos: tragédia em coros. Tradução de Antônio Gonçalves Dias; com notas de Manuel Bandeira; organização de Márcio Suzuki e Samuel Titan Jr. São Paulo: Cosac \& Naify, 2004.

SESC São Paulo. Julia Lemmertz é Mary Stuart no SESC Consolação. Disponível em: < http://www.sescsp.org.br/sesc/revistas/subindex.cfm?Paramend=1\&IDC ategoria $=6248>$, acesso em 29/05/2017.

Simões, Alan Caldas. "Manuel Bandeira: o tradutor". A MARgem - Revista Eletrônica de Ciências Humanas. ano 3, $\mathrm{n}^{0}$ 6, jul./dez, (2010): 72-84.

Simões, Alan Caldas. "Manuel Bandeira: o tradutor". A MARgem - Revista Eletrônica de Ciências Humanas. ano 3, $\mathrm{n}^{0}$ 6, jul./dez, (2010): 72-84.

Vicente, Sebastião. Maria Stuart. Disponível em <http://sopaodotiao.blogspot. com.br/2009/01/maria-stuart.html > , 29/01/2009.

Volobuef, Karin. "Friedrich Schiller e Gonçalves Dias". Pandaemonium Germanicum. 9, (2005): 77-90.

Wyler, L. Linguas, poetas e bacharéis. Uma crônica da tradução no Brasil. Rio de Janeiro: Rocco, 2003.

Recebido em: 16/05/2021

Aceito em: 13/08/2021

Publicado em setembro de 2021

Daniel Martineschen. E-mail: martineschen@gmail.com. ORCID: https://orcid. org/0000-0002-2909-1861. 